\title{
Explosives Detection and Identification by PGNAA
}

\author{
E.H. Seabury \\ A.J. Caffrey
}

April 2006

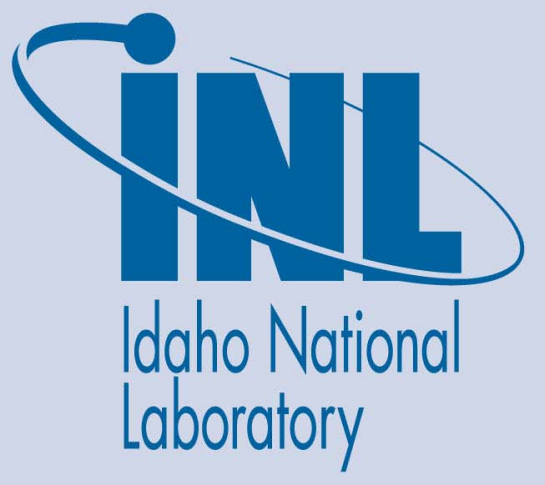

The INL is a U.S. Department of Energy National Laboratory operated by Battelle Energy Alliance 
INL/EXT-06-01210

\title{
Explosives Detection and Identification by PGNAA
}

\author{
E.H. Seabury
}

A.J. Caffrey

April 2006

\section{Idaho National Laboratory \\ Idaho Falls, Idaho 83415}

Prepared for the

U.S. Department of Energy

Office of Nuclear Energy

Under DOE Idaho Operations Office

Contract DE-AC07-05ID14517 


\section{ABSTRACT}

The feasibility of using field-portable prompt gamma-ray neutron activation analysis (PGNAA) to detect and identify explosives in improvised nuclear devices has been studied computationally, using the Monte Carlo NParticle (MCNP) code developed at Los Alamos National Laboratory. The Monte Carlo results, in turn were tested experimentally using explosive simulants and the PINS PGNAA system developed at Idaho National Laboratory (INL). The results of the MCNP calculations and PINS measurements have been previously reported ${ }^{1}$. In this report we describe measurements performed on actual explosives and compare the results with calculations.

The calculations and measurements were in good agreement and indicate that most explosives are readily distinguishable from one another by PGNAA. 


\section{CONTENTS}

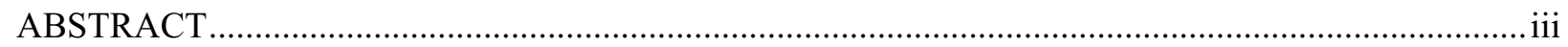

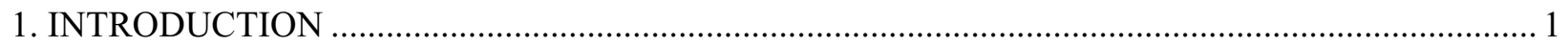

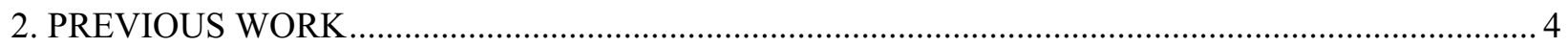

3. PINS MEASUREMENTS AND COMPARISON WITH MCNP ................................................. 6

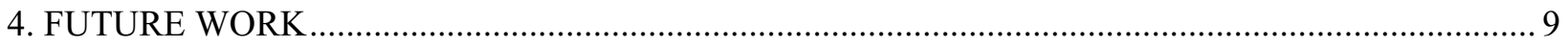

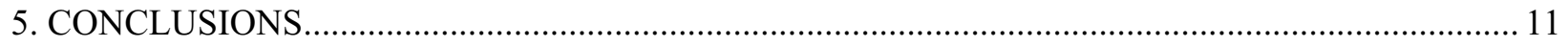

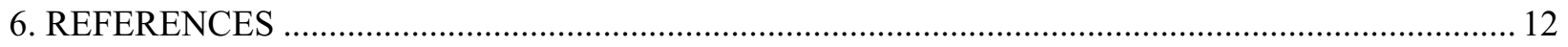

Appendix A

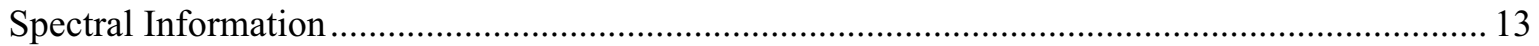

\section{FIGURES}

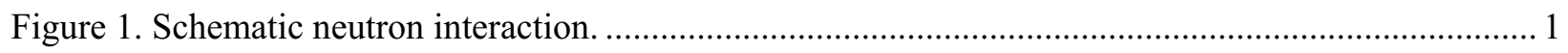

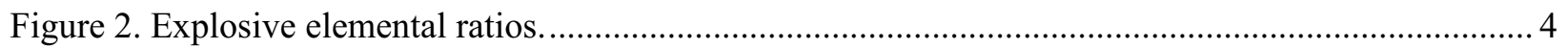

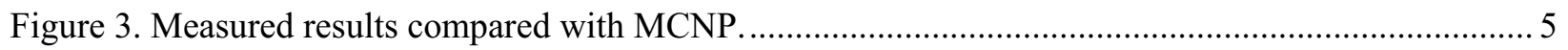

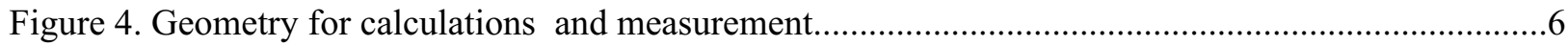

Figure 5. Measured versus calculated elemental ratios........................................................................

Figure 6. Notional explosive analysis graphical user interface screens................................................10

\section{TABLES}

Table 1. Elemental Composition of Explosives in weight percent. ......................................................... 2

Table 2. Designations and Chemical Formulas of Explosives.......................................................... 2

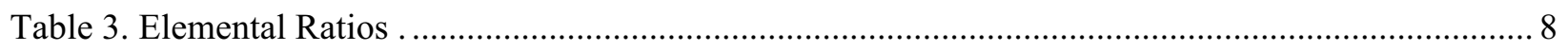

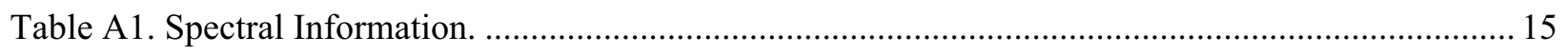




\section{Explosive Detection and Identification by PGNAA \\ 1. INTRODUCTION}

In FY-2003, DOE/NA-42 officials asked us if INL's Portable Isotopic Neutron Spectroscopy System $^{2}$ (PINS) could be adapted to detect and identify explosives, if any, within a suspect improvised nuclear device (IND). In 2004 we reported the results of Monte Carlo calculations and a small set of laboratory experiments to confirm the results. We report here our FY-2005 study of this problem. Our work consisted of a set of laboratory experiments on actual explosives and a small set of calculations using Los Alamos National Laboratory's $\mathrm{MCNP}^{3}$ code.

PINS employs neutron radiation to probe the chemical elements within a container without the need to open or even touch the container. A radoisotopic neutron source or an electrical neutron generator shines neutrons on the item under test. The neutrons, in turn, penetrate the container or munition where they interact with the atomic nuclei of the filler material, producing gamma rays characteristic of the chemical elements inside the item. These energetic gamma rays can penetrate even the thick steel wall of an artillery projectile to escape and trigger a gamma-ray spectrometer. This technique is called Prompt Gamma-ray Neutron Activation Analysis (PGNAA). A schematic neutron reaction event is shown in Figure 1. The energies and intensities of these gamma rays, as measured by the spectrometer, identify the elemental composition of the fill material.

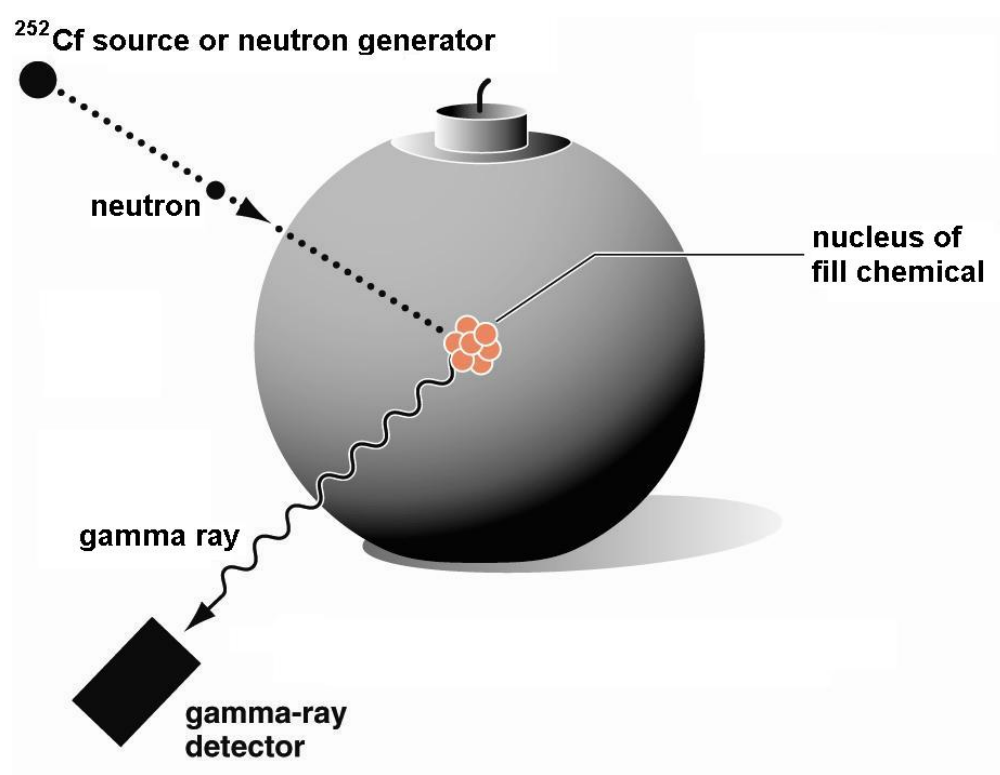

Figure 1. Schematic neutron interaction.

PGNAA has been demonstrated to be an effective tool for identifying contents of munitions and other containers suspected to contain explosives, smoke-generating chemicals, and chemical warfare agents such as mustard and nerve gas, and to this end, PINS is used routinely by the U.S. Army ${ }^{4}$, the Defense Threat Reduction Agency, and foreign military units. 
Identifying explosives of a particular type is somewhat more difficult that identifying chemical warfare agents, however, because most explosives contain just four chemical elements, while the elemental compositions of chemical warfare agents vary broadly. For example, Table 1 shows the compositions $^{5,6}$ of the explosives examined in this project. The chemical formulas and designations of the explosives are shown in Table 2.

Table 1. Elemental Composition of Explosives in weight percent.

\begin{tabular}{lccccccccccc}
\hline & & & & & & & & & \multicolumn{3}{c}{ Black } \\
& HMX & LX-17 & TNT & Comp. B & TATB & PBX-9501 & PBX-9502 & NM & ANFO & Powder & TATP \\
\hline H & 2.7 & 2.2 & 2.2 & 2.7 & 2.3 & 2.9 & 2.2 & 5.0 & 5.4 & - & 8.2 \\
C & 16.2 & 27.5 & 37.0 & 24.3 & 27.9 & 17.7 & 27.6 & 19.7 & 2.6 & 9.3 & 48.6 \\
O & 43.2 & 34.4 & 42.3 & 42.6 & 37.2 & 43.0 & 35.3 & 52.4 & 58.1 & 35.2 & 43.2 \\
N & 37.8 & 30.1 & 18.5 & 30.4 & 32.6 & 36.4 & 31.0 & 23.0 & 33.9 & 10.3 & -- \\
Cl & -- & 1.9 & -- & -- & -- & -- & 1.3 & -- & -- & -- & - \\
F & -- & 2.2 & -- & -- & -- & -- & 1.4 & -- & -- & -- & -- \\
S & -- & -- & -- & -- & -- & -- & -- & -- & -- & 16.5 & -- \\
K & -- & -- & -- & -- & -- & -- & -- & -- & -- & 28.7 & -- \\
\hline
\end{tabular}

Table 2. Designations and Chemical Formulas of Explosives

\begin{tabular}{|c|c|c|}
\hline Designation & Chemical Formula & Chemical Name \\
\hline HMX & $\mathrm{C}_{4} \mathrm{H}_{8} \mathrm{~N}_{8} \mathrm{O}_{8}$ & Octahydro-1,3,5,7-tetranitro-1,3,5,7-tetrazocine \\
\hline LX-17 & $92.5 \%$ TATB, $7.5 \%$ Kel-F $800\left(\mathrm{C}_{8} \mathrm{H}_{2} \mathrm{Cl}_{3} \mathrm{~F}_{11}\right)_{\mathrm{n}}$ & LX-17-0 \\
\hline TNT & $\mathrm{C}_{7} \mathrm{H}_{5} \mathrm{~N}_{3} \mathrm{O}_{6}$ & 2-methyl-1,3,5-trinitrobenzene \\
\hline Composition B & $63 \% \operatorname{RDX}\left(\mathrm{C}_{3} \mathrm{H}_{6} \mathrm{~N}_{6} \mathrm{O}_{6}\right), 36 \%$ TNT, $1 \%$ wax & -- \\
\hline TATB & $\mathrm{C}_{6} \mathrm{H}_{6} \mathrm{~N}_{6} \mathrm{O}_{6}$ & 2,4,6-trinitro-1,3,5-benzenetriamine \\
\hline PBX-9501 & $\begin{array}{c}\text { 95\% HMX, } 2.5 \% \text { Estane }\left(\mathrm{C}_{5.14} \mathrm{H}_{7.50} \mathrm{~N}_{0.19} \mathrm{O}_{1.76}\right)_{\mathrm{n}} \\
2.5 \% \text { BDNPA-F }\end{array}$ & -- \\
\hline PBX-9502 & 95\% TATB, 5\% Kel-F 800 & -- \\
\hline NM & $\mathrm{CH}_{3} \mathrm{NO}_{2}$ & Nitromethane \\
\hline ANFO & $95 \%$ Ammonium Nitrate $\left(\mathrm{H}_{4} \mathrm{~N}_{2} \mathrm{O}_{3}\right), 5 \%$ fuel oil & Ammonium nitrate-fuel oil mixture \\
\hline Black Powder & $75 \% \mathrm{KNO}_{3}, 15 \%$ charcoal, $10 \%$ sulfur & -- \\
\hline TATP & $\mathrm{C}_{9} \mathrm{H}_{18} \mathrm{O}_{6}$ & Triacetonetriperoxide \\
\hline
\end{tabular}


As can be seen in the tables explosives consist largely of the same elements (carbon, hydrogen, oxygen, and nitrogen) in differing ratios, the major exceptions being the chlorine-bearing explosives LX17 and PBX-9502, and the non-nitrogenous explosive TATP. The key therefore to explosive identification is in the ability to determine the relative concentrations of the key elements carbon, hydrogen, oxygen, and nitrogen.

In order to examine the feasibility of measuring relative concentrations of these elements, the PGNAA process was studied using MCNP in 2004. The results of those calculations were compared with laboratory measurements of simulated explosives using a PINS system. 


\section{PREVIOUS WORK}

The previous work in this project consisted of studying the various neutron sources, likely explosive types, and the response of a PGNAA system using the MCNP code. It was determined that most explosives could be readily distinguished from one another if a DT neutron generator were used, as opposed to a DD neutron generator or 252-Californium source. The most likely method of spectrum analysis was also determined, i.e. what gamma-spectrum features would be used to distinguish the various explosives.

It was determined in 2004 that the geometry of the explosives would not affect their identification if elemental ratios were used as primary means of identification. In particular if one used the gamma-ray peak areas of gamma rays produced by inelastic scattering, or the ratio of two peak areas produced by thermal neutron capture, then the effects of explosive geometry would be minimized The results of using the ratios of carbon-to-oxygen and hydrogen-to-nitrogen are shown in Figure 2. In the figure, the ratios are plotted for each explosive type using three different masses, $5 \mathrm{~kg}, 10 \mathrm{~kg}$, and $15 \mathrm{~kg}$. As can be seen, the explosive mass does not significantly affect the ratios. In addition to testing different masses and geometric configurations of explosives, we previously examined the effects of inserting a plug of uranium inside a mass of explosives and determined that there were no appreciable changes in the elemental ratios.

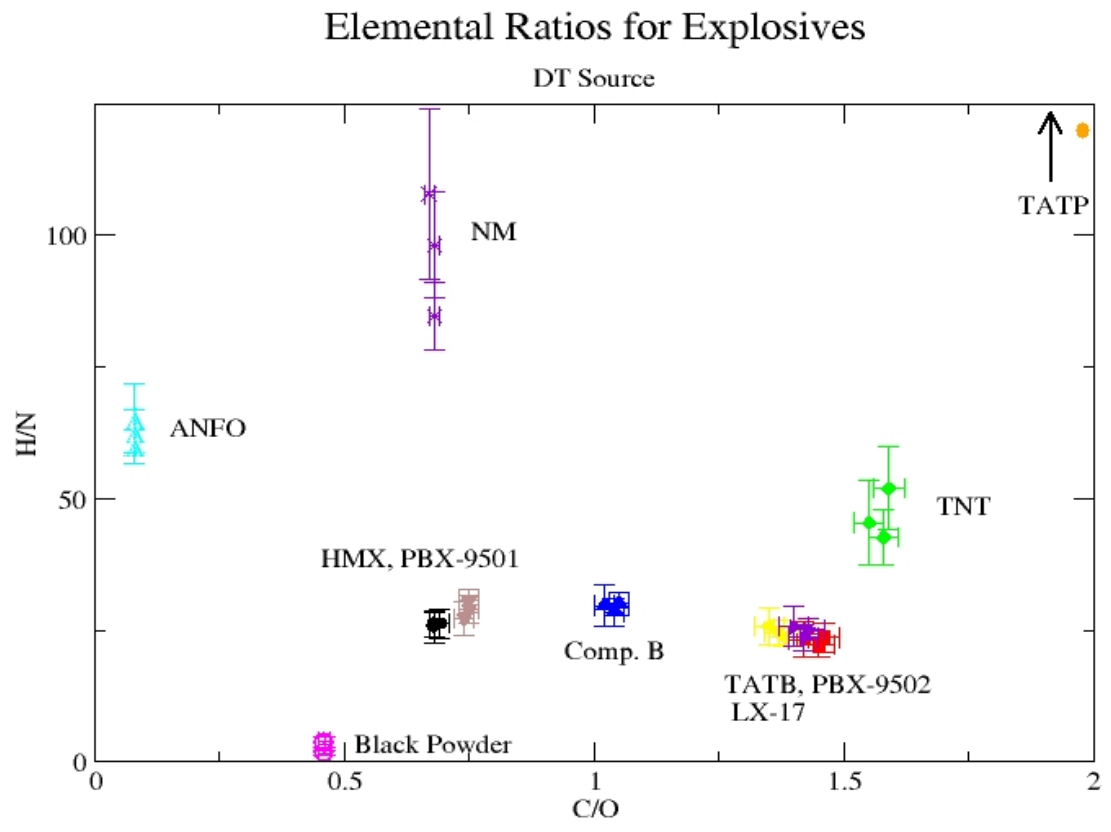

Figure 2. Explosive elemental ratios.

In order to compare with calculation, a short series of measurements were performed on explosive simulants of HMX, LX-17, and COMP. B. The simulants were composed of innocuous materials such as melamine, graphite and salt in order to obtain elemental compositions close to that of the actual explosives. The densities of the simulants were significantly lower than the actual explosives however, on the order of $1.0 \mathrm{~g} / \mathrm{cc}$ as opposed to $1.9 \mathrm{~g} / \mathrm{cc}$. The results of the measurements and the MCNP calculations 
are shown in Figure 3. As can be seen in the figure, there was good agreement between the measurement and the calculation.

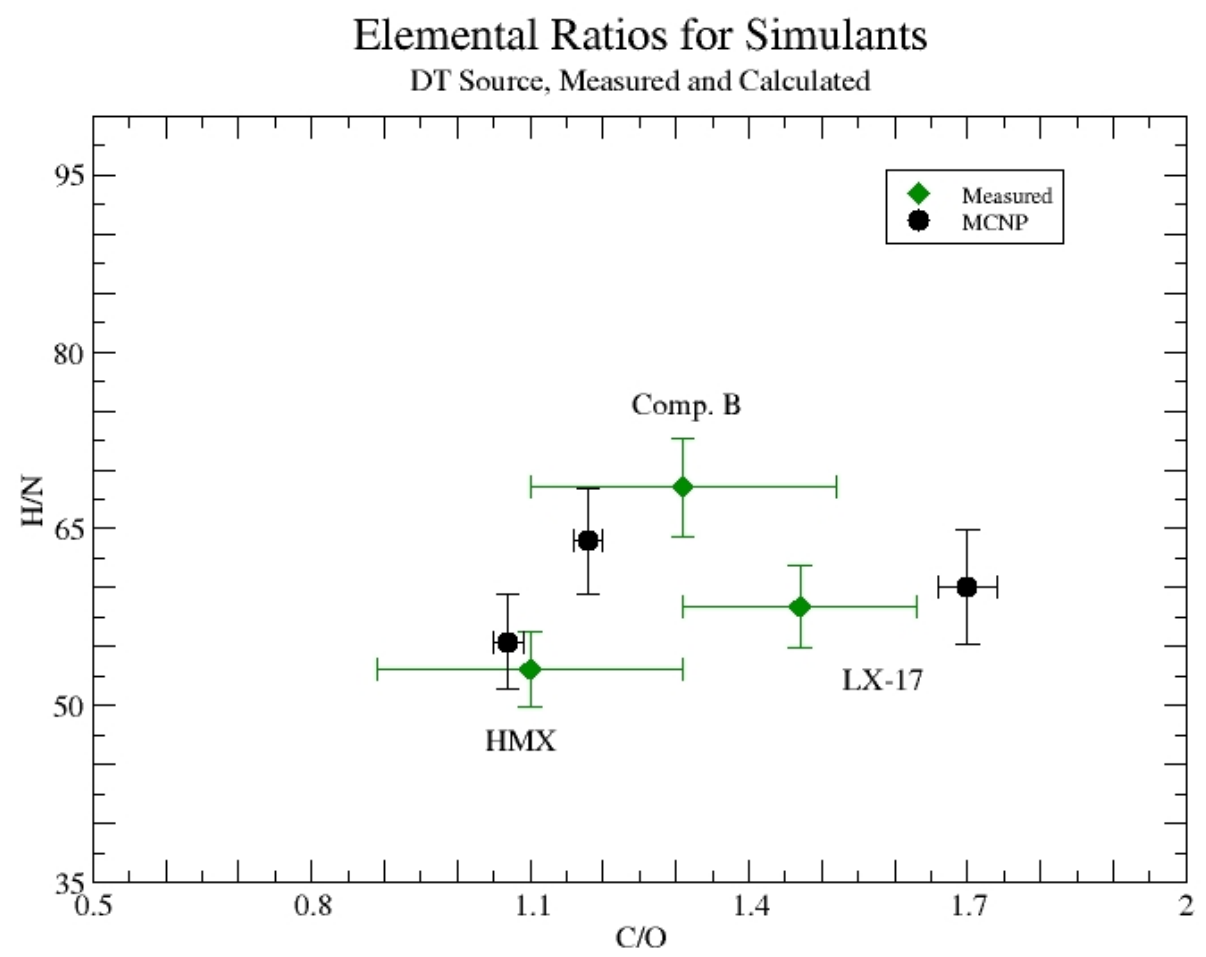

Figure 3. Measured results compared with MCNP. 


\section{PINS MEASUREMENTS AND COMPARISON WITH MCNP}

The current work consisted of a series of measurements and calculations on actual explosives. The explosives anfo, composition B, C-4, PBX-9501, and PBX-9502 were examined both in the laboratory and in simulation. The geometry for the calculations and measurements is shown in Figure 4. The apparatus consisted of the following:

- Ortec GMX 45\% HPGe detector

- Ortec Digidart Multichannel Analyzer

- Sodern Genie 16C Field Portable DT Neutron Generator

- Panasonic Toughbook laptop computer

- Detector stand, polyethylene moderator block, and shielding

All of the equipment used in the experiment was field portable. The digidart and notebook computer can be run on battery power, and the neutron generator uses a $12 \mathrm{~V}$ power supply (vehicle cigarette lighter).

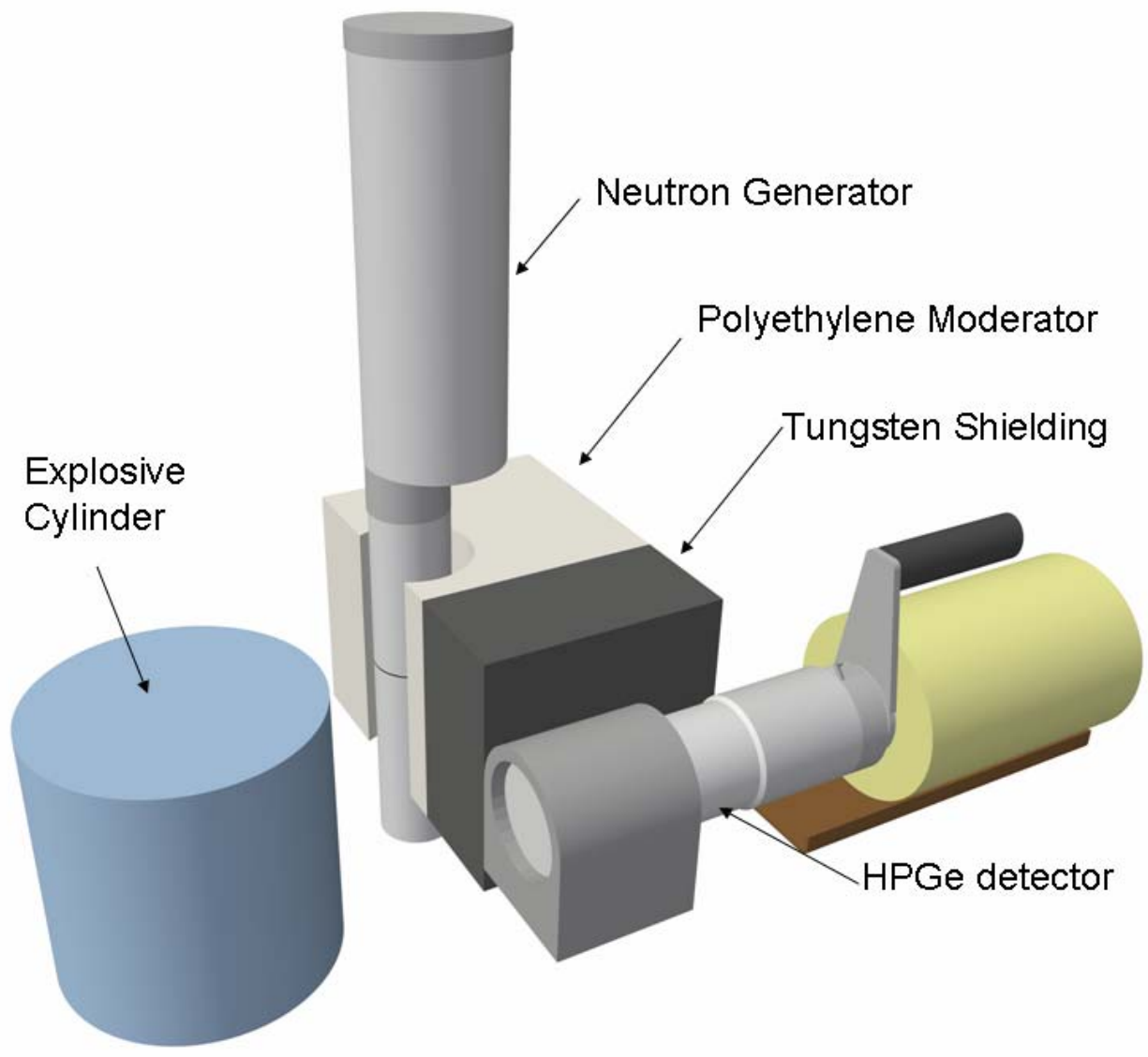

Figure 4: Geometry for calculations and measurement 
Approximately 15-kg of each explosive was used. Gamma-ray spectra were measured for each explosive and peak area information was extracted to determine the elemental ratios. The gamma-ray peak information for each explosive is shown in Appendix A. A plot of the measured hydrogen-tonitrogen versus carbon-to-oxygen ratios is shown in Figure 6. These data are also shown in Table 3. The measured data in the table have been normalized to the model results in order to account for detector efficiency.

\section{Elemental Ratios for Explosives}

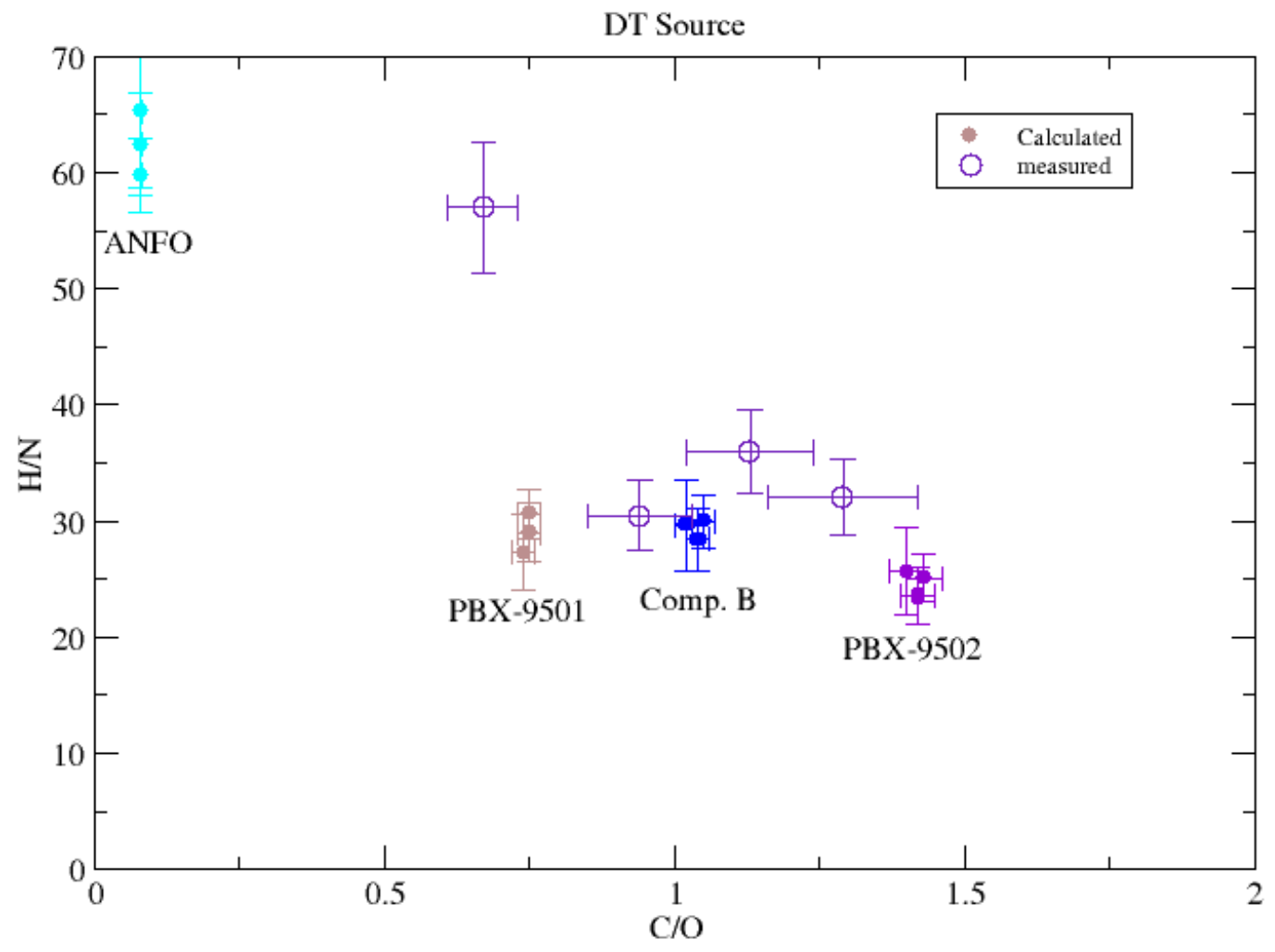

Figure 5: Measured versus calculated elemental ratios 
Table 3: Elemental ratios

\begin{tabular}{llllll}
\hline & C/O-Model & C/O measured & H/N Model & H/N measured & Cl detected? \\
\hline Anfo & 0.11 & $0.67 \pm .07$ & 59.53 & $57.0 \pm 2.7$ & No \\
C-4 & 1.03 & $0.56 \pm .04$ & 48.79 & $27.9 \pm 1.4$ & No \\
Comp B. & 1.07 & $1.29 \pm .07$ & 35.26 & $37.2 \pm 4.4$ & No \\
PBX-9501 & 0.78 & $0.94 \pm .06$ & 31.37 & $32.6 \pm 3.8$ & No \\
PBX-9502 & 1.45 & $1.13 \pm .06$ & 30.96 & $35.9 \pm 4.0$ & Yes \\
\hline
\end{tabular}

As can be seen there is general agreement between the MCNP calculations and the measurements with the exception of C-4. Both the hydrogen-to-nitrogen and carbon-to-oxygen ratios for C-4 differ significantly between calculation and experiment. The most likely cause of this is a deviation between the formulation of the explosive in the model and the experiment. Indeed, the explosive labeled "C-4" is granular in form, and it does not have the consistency of modeling clay familiar to one of the authors from his days in the Army.

Unlike the other explosives used in these measurements, PBX-9502 uses chlorine-containing Kel$\mathrm{F}$ as a binder. It should be noted that chlorine was detected in the PBX-9502 measurement, helping to distinguish it from the other explosives. 


\section{FUTURE WORK}

The study reported here shows that the PGNAA technique is very suitable for determining the type of explosive found in an improvised nuclear device. Future work will optimize details of both the measurement techniques and analysis of the gamma spectra and includes the following:

- A larger set of measurements on real explosives is needed, allowing a statistical interpretation of future measurement, providing a confidence level on a given measurement.

- Additional explosive types such as TNT and dynamite will be measured, now that they are available at INL.

- The data acquisition software will be integrated with a new user interface showing the results of a particular measurement. A proposed set of interface screens is shown in Figure 7. In the figure, as the data acquisition progresses, the hydrogen-to-nitrogen and carbonto-oxygen bands on the screen narrow and darken, until they converge on the most likely explosive type. This data acquisition and analysis package will be designed to be operated by technicians.

- Once the software has been optimized we intend to perform a series of blind tests on actual explosives. The equipment would be operated by military personnel, and a variety of explosive types and sizes would be examined. Data would be interpreted online, and later undergo an "expert" analysis offline in order to test the analysis algorithms 

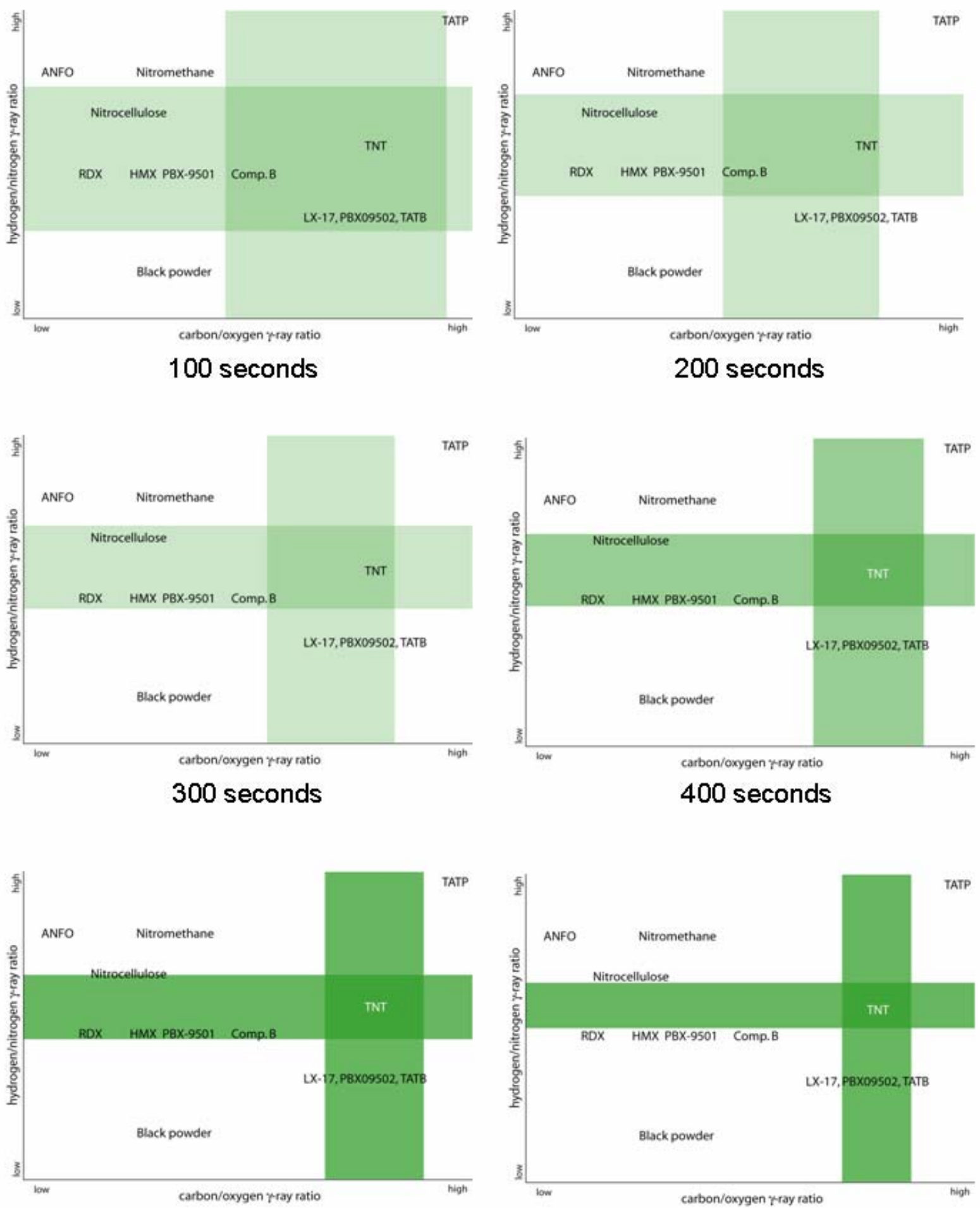

500 seconds

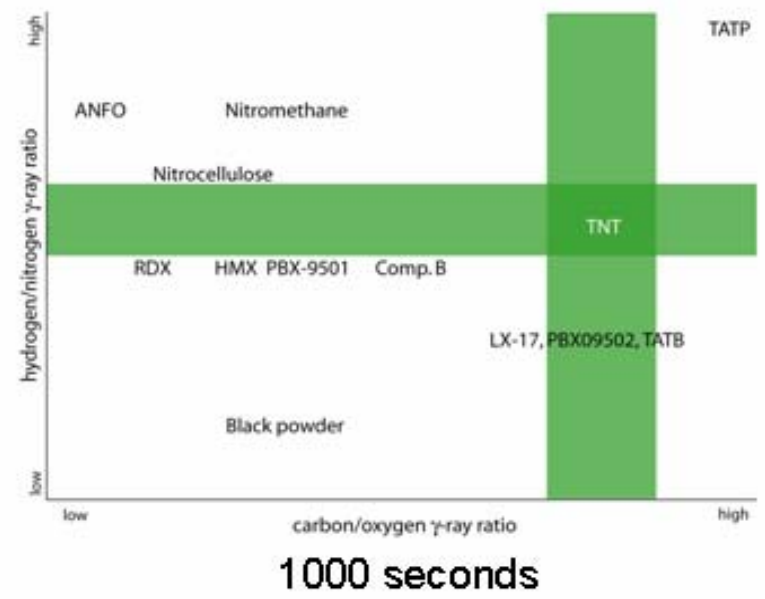

Figure 6: Notional explosive analysis graphical user interface screens 


\section{CONCLUSIONS}

The use of the PGNAA techniques to measure elemental ratios allows a large degree of discrimination among various types of explosives. The ratios of hydrogen-to-nitrogen and carbon-tooxygen allow one to distinguish between different explosive types and the detection of other elements, such as chlorine in the case of PBX-9502, allow further discrimination. There is some discrepancy between the MCNP calculations and the measurements, but additional measurements of the real explosives will allow a database to be developed that will aid in the identification of real explosives, and provide a confidence level in the results of a given measurement. 


\section{REFERENCES}

1. E.H. Seabury and A.J. Caffrey, Explosive Detection and Identification by PGNAA, Idaho National Laboratory Report INEEL/EXT-05-02475, November 2004.

2. A.J. Caffrey, J.D. Cole, R.J. Gehrke, and R.C. Greenwood, "Chemical warfare agent and high explosive identification by spectroscopy of neutron-induced gamma rays," IEEE Transactions on Nuclear Science 39 (1992) p. 1422-1426

3. X-5 Monte Carlo Team, "MCNP-A General Monte Carlo N-Particle Transport Code, Version 5," Los Alamos National Laboratory report LA-UR-03-1987 (2003).

4. A.J. Caffrey et al., "U.S. Army Experience with the PINS Chemical Assay System," Idaho National Engineering Laboratory report EGG-NRP-1143 (1994).

5. S. Budavari, ed., The Merck Index, Eleventh Edition (Rahway, N.J.: Merck \& Co., Inc., 1989).

6. B. M. Dobratz, LLNL Explosives Handbook UCRL-52997, 1981. 
Appendix A

Spectral Information 


\section{Appendix A}

\section{Spectral Information}

\section{DT Source}

15-KG

\begin{tabular}{llllllllll}
\multicolumn{1}{c}{ Explosive } & H-2223 Area & Unc. & C-4451 Area & Unc. & N-sum Area & Unc. & O-6129 Area & Unc. \\
\hline Anfo & 109273 & 330 & 4647 & 306 & 727 & 34 & 23725 & 1635 \\
C-4 & 42199 & 205 & 4673 & 345 & 696 & 35 & 22980 & 205 \\
Comp. B & 23410 & 153 & 4254 & 203 & 158 & 19 & 12558 & 149 \\
PBX-9501 & 23811 & 154 & 3579 & 243 & 177 & 21 & 12749 & 148 \\
PBX-9502 & 20612 & 144 & 4300 & 237 & 188 & 21 & 13438 & 144
\end{tabular}

